\title{
Depression in Dialysis: A Poor Prognostic Factor and the Mech- anism behind It
}

\section{Umme Salma Talukder ${ }^{1}$, Hossain Tameem Bin Anayet ${ }^{2 *}$, Samjhana Mandal ${ }^{2}$, Fahmida Ahmed ${ }^{3}$, Muhammad Ayaaz Ibrahim ${ }^{4}$ and Samira Humaira Habib ${ }^{5}$}

${ }^{1}$ Consultant Psychiatrist, Kulhudhuffushi Regional Hospital (KRH), Maldives

${ }^{2}$ Research Assistant, Department of Biological Sciences, University of Toronto, Canada

${ }^{3}$ Professor, Head, Department of Psychiatry, Ibn Sina Medical College, Bangladesh

${ }^{4}$ Medical Officer, Hitech Modern Psychiatric Hospital, Bangladesh

${ }^{5}$ Principal Research Officer, Health Economics Unit, BIRDEM, Bangladesh

*Corresponding author: Hossain Tameem Bin Anayet, Research Assistant, Department of Biological Sciences, University of Toronto, Canada

\begin{abstract}
Major Depressive Disorder (MDD) is one of the most common psychiatric illnesses. The effect of depression on one's physical health is well-known, which can include anything from weight gain or loss to chronic illnesses such as heart disease, kidney or gastrointestinal problems. Provided the increasing prevalence of patients suffering from End Stage Renal Disease (ESRD) and receiving dialysis treatment, it is important to investigate how MDD affects the outcome of their treatment. The incidence of depression in dialysis patients ranges from $10 \%$ to $66 \%$ in various studies, with prevalence reaching as high as $100 \%$. The purpose of this article is to find the prevalence and severity of major depressive disorder in dialysis patients as well as to describe the possible pathways MDD worsens the dialysis outcome. Our study population consisted of 51 End Stage Renal Disease (ESRD) patients sampled from the Department of Nephrology at BIRDEM General Hospital. Neurocognitive, physical symptoms, the severity of MDD and presence of comorbid conditions including diabetics and hypertension, were measured in our study. The ESRD patient sample consisted $47.7 \%$ moderately depressed patients, $34 \%$ severely depressed, $11.4 \%$ mild and $6.8 \%$ with minimal MDD patients. Analogous to Hypertension and Diabetic patients with depression, the number of Chronic Kidney Disease (CKD) patients with mostly moderate severe depression increased with the duration of the disease. The article explains a myriad of biologic, behavioral, genetic and social factors underlying the association of depression and adverse medical outcomes in patients with CKD and ESRD. Moreover,
\end{abstract}

neuroimaging data is analyzed to further discuss the relationship between Depression and CKD. The implication of this study is to emphasize the importance of dialysis patients' overall health and to serve as a building block for further research into depression in dialysis patients.

\section{Keywords}

Compound depression, Major depressive disorder (MDD), Major depressive episode (MDE), Dialysis, End stage renal disease (ESRD), Chronic kidney disease (CKD)

\begin{abstract}
Abbreviations
MDD: Major Depressive Disorder; MDE: Major Depressive Episode; HD: Hemodialysis; rCBF: Right Cerebral Blood Flow; ESRD: End Stage Renal Disease; CKD: Chronic Kidney Disease; RRT: Renal Replacement Therapy; DSM-V: Diagnostic and Statistical Manual of Mental Disorders; BDI II: Beck Depression Inventory Second Edition; DM: Diabetes Mellitus; HTN: Hypertension; AKI: Acute Kidney Injury; WMHs: White Matter Hyperintensities; IHD: Ischemic Heart Disease; MRI: Magnetic Resonance Imaging
\end{abstract}

\section{Introduction}

There are approximately two million End Stage Renal Disease (ESRD) patients worldwide, who regularly receive Renal Replacement Therapy (RRT) in the form of dialysis $[1,2]$. People with depression will have $85 \%$ more chance of developing renal failure [3]. The etiology of compound depression in ESRD is dynamic compli-

Citation: Talukder US, Anayet HTB, Mandal S, Ahmed F, Ibrahim MA, et al. (2020) Depression in Dialysis: A Poor Prognostic Factor and the Mechanism behind It. Int J Depress Anxiety 3:019. doi. org/10.23937/2643-4059/1710019

Accepted: February 24, 2020: Published: February 26, 2020

Copyright: (C) 2020 Talukder US, et al. This is an open-access article distributed under the terms of the Creative Commons Attribution License, which permits unrestricted use, distribution, and reproduction in any medium, provided the original author and source are credited. 
cated by both neurocognitive and somatic features [2]. Depression is often unrecognized [3], reflecting a lack of routine psychological evaluation among this patient population [4]. The consequences of unidentified depression among dialysis patients are significant. Co-morbid depressive illnesses amplify the impact of chronic illnesses, increasing functional disability as well as the use of healthcare services. Most common psychopathological condition occurring in patients with Hemodialysis (HD) is depression [5-7]. This article describes the possible pathways MDD worsens the dialysis outcome.

\section{Methodology}

This was an observational cross-sectional and prospective study on recently diagnosed ESRD patients. 51 ESRD patients were sampled from Department of $\mathrm{Ne}$ phrology at BIRDEM General Hospital. Informed written consent was taken and privacy was maintained. Diagnostic and Statistical Manual of mental disorders (DSM-V) was used as a diagnostic tool. Major Depressive Disorder (MDD) was graded as minimal, mild, mode-

Table 1: Socio-demographic parameters of the study subjects.

\begin{tabular}{|c|c|c|c|}
\hline \multicolumn{2}{|l|}{ Parameters } & \multirow{2}{*}{\begin{tabular}{|l} 
Frequency \\
25 \\
\end{tabular}} & \multirow{2}{*}{$\begin{array}{l}\text { Percentage } \\
(\%)\end{array}$} \\
\hline Sex & Male & & \\
\hline & Female & 26 & 49.1 \\
\hline \multirow{3}{*}{$\begin{array}{l}\text { Age (in } \\
\text { years) }\end{array}$} & $>30$ & 1 & 1.9 \\
\hline & $30-50$ & 14 & 26.4 \\
\hline & 50 and above & 34 & 64.2 \\
\hline \multirow{3}{*}{$\begin{array}{l}\text { Marital } \\
\text { status }\end{array}$} & Married & 44 & 83 \\
\hline & Unmarried & 1 & 1.9 \\
\hline & Widow & 1 & 1.9 \\
\hline \multirow{3}{*}{$\begin{array}{l}\text { Occupation } \\
\text { status }\end{array}$} & Employed & 11 & 20.8 \\
\hline & Unemployed & 11 & 20.8 \\
\hline & Widow & 23 & 43.4 \\
\hline \multirow[t]{3}{*}{ Habitat } & Urban & 26 & 49.1 \\
\hline & Rural & 16 & 30.2 \\
\hline & Semi Urban & 4 & 7.5 \\
\hline \multirow{5}{*}{$\begin{array}{l}\text { Educational } \\
\text { status }\end{array}$} & Uneducated & 3 & 5.7 \\
\hline & Below SSC & 23 & 37.7 \\
\hline & SSC $^{*}$ & 7 & 13.2 \\
\hline & $\mathrm{HSC}^{\star}$ & 8 & 15.1 \\
\hline & Graduate & 7 & 13.2 \\
\hline \multirow{3}{*}{$\begin{array}{l}\text { Monthly } \\
\text { income (in } \\
\text { BDT) }\end{array}$} & Less than 10000 & 2 & 3.8 \\
\hline & 10000 & 6 & 11.3 \\
\hline & 20000 and above & 34 & 64.2 \\
\hline \multirow{4}{*}{$\begin{array}{l}\text { Family } \\
\text { members }\end{array}$} & 2 & 2 & 3.8 \\
\hline & 3 & 3 & 5.7 \\
\hline & 4 & 10 & 18.9 \\
\hline & More than 5 & 27 & 50.9 \\
\hline
\end{tabular}

"SSC: Secondary School Certificate (equivalent of grade 10 completion; "HSC: Higher Secondary School Certificate (equivalent of grade 12 completion). rate and severe by Beck Depression Inventory. The Beck Depression Inventory Second Edition (BDI II) was a 21 items self-report instrument for measuring the severity of Depression in adults and adolescents aged 13 years and above. Exclusion criteria included refusal to participate in the psychiatric interview, patients who were diagnosed with psychiatric disorders other than MDD and patients with prior history of any psychiatric illness. A single psychiatrist interviewed all study subjects.

\section{Results}

The following co-morbid conditions were present among the study subjects- Alport syndrome, Epilepsy, Kidney TB, Antral gastritis, Acute Respiratory Failure (ARF), Obstructive sleep apnea, Ischemic Heart Disease (IHD), Acute Suppurative Otitis Media (ASOM), Electrolyte imbalance, Chronic Glomerulonephritis (CGN), Hyperkalemia, hyperparathyroidism, Coronary Artery Bypass Graft (CABG), Cholelithiasis, Hypoalbuminemia, Hypokalemia, Hypothyroidism Urinary tract infection, Asthma, Diabetic retinopathy, Fracture, Xerotic dermatitis, Eczema, Pulmonary Tuberculosis (PTB). Hemorrhoids, Sepsis, Stroke, Facial palsy, Thyroidectomy, Benign Enlargement of Prostate (BEP). The most frequent comorbid condition was Diabetes and Hypertension and followed by Ischemic Heart Disease (IHD) which constitutes around 13.5\% of the study subjects.

All the patients in the study population had Diabetes Mellitus (DM), Hypertension (HTN) and Major Depressive Disorder (MDD). Table 1 is showing the sociodemographic parameters of the study sample which belongs to the moderate socioeconomic class with the bulk educated up to less than HSC and mostly male. Table 2 gives the picture of CKD with depres-

Table 2: Frequency distribution of depression and duration of CKD.

\begin{tabular}{|l|l|l|l|l|}
\hline \multirow{2}{*}{$\begin{array}{l}\text { MDD } \\
\text { severity }\end{array}$} & \multicolumn{4}{|l|}{ Duration of CKD } \\
\cline { 2 - 5 } & $\mathbf{1}$ year & $\mathbf{2 - 5}$ yrs & More than 5 & Total \\
\hline Minimal & $0(0.0 \%)$ & $1(3.1 \%)$ & $0(0.0 \%)$ & $1(3.1 \%)$ \\
\hline Mild & $1(3.1 \%)$ & $1(3.1 \%)$ & $1(3.1 \%)$ & $3(9.4 \%)$ \\
\hline Moderate & $7(21.9 \%)$ & $10(31.2 \%)$ & $3(9.4 \%)$ & $20(62.5 \%)$ \\
\hline Severe & $1(3.1 \%)$ & $6(18.8 \%)$ & $1(3.1 \%)$ & $8(25 \%)$ \\
\hline Total & $9(28.1 \%)$ & $18(56.2 \%)$ & $5(15.6 \%)$ & $32(100 \%)$ \\
\hline
\end{tabular}

Table 3: Frequency distribution of depression with the duration of DM.

\begin{tabular}{|l|l|l|l|l|}
\hline \multirow{2}{*}{$\begin{array}{l}\text { MDD } \\
\text { severity }\end{array}$} & \multicolumn{3}{|l|}{ Duration of DM } \\
\cline { 2 - 5 } & $\mathbf{1 - 3}$ year & $\mathbf{3 - 1 0}$ yrs & $\mathbf{1 0}$ and < 10 & Total \\
\hline Minimal & $0(0.0 \%)$ & $1(2.4 \%)$ & $3(7.1 \%)$ & $4(9.5 \%)$ \\
\hline Mild & $0(0.0 \%)$ & $0(0.0 \%)$ & $4(9.5 \%)$ & $4(9.5 \%)$ \\
\hline Moderate & $2(4.8 \%)$ & $2(4.8 \%)$ & $17(40.5 \%)$ & $21(50 \%)$ \\
\hline Severe & $0(0.0 \%)$ & $1(2.4 \%)$ & $12(28.6 \%)$ & $13(31 \%)$ \\
\hline Total & $2(4.8 \%)$ & $4(9.6 \%)$ & $36(85.5 \%)$ & $42(100 \%)$ \\
\hline
\end{tabular}


Table 4: Frequency distribution of depression with the duration of Hypertension.

\begin{tabular}{|l|l|l|l|l|}
\hline MDD severity & Duration of Hypertension & \multicolumn{1}{l|}{} \\
\hline & $\mathbf{1 - 3}$ year & $\mathbf{3 - 1 0}$ yrs & 10 and < 10 & Total \\
\hline Minimal & $2(4.9 \%)$ & $2(4.9 \%)$ & $0(0.0 \%)$ & $4(9.8 \%)$ \\
\hline Mild & $0(0.0 \%)$ & $2(4.9 \%)$ & $2(4.9 \%)$ & $4(9.8 \%)$ \\
\hline Moderate & $3(7.3 \%)$ & $7(17.1 \%)$ & $12(29.3 \%)$ & $22(53.7 \%)$ \\
\hline Severe & $1(2.4 \%)$ & $6(14.6 \%)$ & $4(9.8 \%)$ & $11(26.8 \%)$ \\
\hline Total & $6(14.6 \%)$ & $17(41.5 \%)$ & $18(43.9 \%)$ & $41(100 \%)$ \\
\hline
\end{tabular}

Table 5: Co-morbid condition and depression among the study subjects.

\begin{tabular}{|c|c|c|c|c|}
\hline \multicolumn{2}{|l|}{ Parameters } & \multirow{2}{*}{\begin{tabular}{|l} 
Duration (in years) \\
$1-3$
\end{tabular}} & \multicolumn{2}{|c|}{ Number of patients with MDD } \\
\hline \multirow[t]{9}{*}{ Co-morbid condition } & \multirow[t]{3}{*}{ Diabetes } & & $2(4.8)$ & \\
\hline & & $3-10$ & $5(11.9 \%)$ & \\
\hline & & $>10$ & $35(83.3)$ & Total $42(100 \%)$ \\
\hline & \multirow[t]{3}{*}{ Hypertension } & $1-3$ yrs & $7(17.1 \%)$ & \\
\hline & & $3-10$ & $17(41.5 \%)$ & \\
\hline & & $>10$ yrs & $17(41.5 \%)$ & Total $41(100 \%)$ \\
\hline & \multirow[t]{3}{*}{ Chronic Kidney Disease } & $1 \mathrm{yr}$ & $10(28.6 \%)$ & \\
\hline & & $2-5$ yrs & $17(48.6 \%)$ & \\
\hline & & $>5$ yrs & $8.75(25.0 \%)$ & Total $35(100 \%)$ \\
\hline
\end{tabular}

Table 6: Severity of depression among the study subjects.

\begin{tabular}{|l|l|}
\hline Depression Severity & Frequency (percentage) \\
\hline Minimal & $3(6.8 \%)$ \\
\hline Mild & $5(11.4 \%)$ \\
\hline Moderate & $21(47.7 \%)$ \\
\hline Severe & $15(34.1 \%)$ \\
\hline Total & $44(100 \%)$ \\
\hline
\end{tabular}

sion with mostly moderate severity and the number increasing with the duration of kidney disease i.e. from 2 to 5 years. Table 3, Table 4 and Table 5 is indicating that the study sample has mostly moderate MDD, which increases with the duration of DM and HTN i.e. from 10 years onwards. According to Table 6, we had 44 MDD patients. Most of the patients were moderately depressed $47.7 \%$. 34\% were severely depressed. $11.4 \%$ and $6.8 \%$ had mild and minimal MDD consecutively.

\section{Discussion}

This research result coincides with the studies done abroad and sparse information is found from articles at home. Neurocognitive, physical symptoms [4-6] and the severity of MDD are measured in our study. Depression increase the risk of chronic diseases such as diabetes, chronic heart disease, and heart failure with their accompanying complex medical regimen and polypharmacy. Other pathways include poor adherence to medi- cal regimen and other adverse health behaviors such as smoking and alcohol overuse. Depression is also related to delay health care-seeking behaviors, difficulties in patient-physician communications, and possibly medical errors leading to Acute Kidney Injury (AKI). Substantial variability is noted in the consideration of depression severity. Some studies indicated that moderate depressive syndromes are common in approximately $25 \%$ of ESRD patients, and that severe major depression in 5\%$22 \%$ of ESRD patients, coinciding with the present study. Dialysis is an unstable and critical period, and that levels of depression may change over time [5].

\section{Mechanisms by which depression associates with adverse outcome}

There are several potential biologic mechanisms that can explain the association between depression and poorer medical outcomes in patients with CKD and ESRD. Depression can increase inflammation, which in turn can accelerate atherosclerosis and potentially lead to cardiovascular events. Depression is also implicated in the modulation of vascular tone by altering serotonin levels and autonomic nervous system function, increasing platelet aggregation, altering cortisol and norepinephrine production, all of which can lead to cardiovascular events and stroke. There are also behavioral consequences of depression, which may adversely affect medical outcomes. In patients with ESRD, depression has been associa- 
ted with medication noncompliance, dietary indiscretion, interdialytic weight gain, and missed dialysis. In a study of 65 hemodialysis patients and 94 kidney transplant patients, Cukor, et al. evaluated the association between psychological measures and self-reported medication adherence, and found that depressive symptoms are a significant independent predictor of lower medication adherence [8]. Furthermore, in a study of 295 hemodialysis patients by Kimmel, et al. worsening depressive symptoms are correlated with worse compliance with total dialysis time [3]. Noncompliance with self-care behaviors could worsen blood pressure, blood glucose, cholesterol, bone metabolism, anemia, phosphorus, and volume status in patients with CKD and ESRD, and ultimately lead to adverse health outcomes [7]. Hypothesized mechanisms include biologic, behavioral, genetic, and social factors [1], ranging from inflammatory factors (e.g., C-reactive protein, cytokines) or chemical imbalances (e.g., higher levels of phosphorus, uremia and lower levels of hemoglobin [2], hormones like high levels of cortisol, etc.) to physical inactivity and lack of social support [4,9]. There is evidence of an association between Malnutrition, Inflammation, And Atherosclerosis (MIA) in ESRD patients, and some researchers have suggested that depression might be involved in the MIA syndrome. Others have demonstrated frequent and close relationships between serum albumin levels and depression [9].

Depression is associated with dialysis shift, psychological and social factors [2] which include feelings of hopelessness, perceptions of loss and lack of control, job loss, and altered family and social relationships. Approximately $60 \%-97 \%$ of patients on HD experience some fatigue, which is negatively correlated with quality of life [5]. In a study, $83.49 \%$ of harem dialyzed patients have depressive disorders, including $54.85 \%$ mild and $28.64 \%$ moderate depression. In the subgroup of peritoneal dialyzed patients, moderate depression is identified in $15.63 \%$ of respondents [10]. In another study [11] on 241 Maintenance Haemodialysis (MHD) patients in Boston (USA) area, 57 (23.7\%) participants with significant depressive symptoms are found. In another research, 323 patients with End Stage Renal Disease (ESRN) were compared with a control group of primary health care patients [12]. The group of patients with end stage renal disease got significantly higher scores in (Beck Depression Inventory) BDI [13] compared to primary health care patients. The BDI results indicate that depression is present in patients with mild or medium renal insufficiency. The incidence of depression in dialysis patients ranges from $10 \%$ to $66 \%$ in various studies $[4,14-20]$.

Depressive disorder is the most frequently described psychiatric condition in patients with End-Stage Renal Disease (ESRD). Prevalence can be as high as $100 \%$ [21]. Depression predicts subsequent rapid de- cline in kidney function, in new onset clinically severe kidney disease (or end-stage renal disease), and hospitalizations that are complicated by acute kidney injury [22]. Substance abuse, alcoholism and suicidal tendency are common in depressive illness. Moreover, they are likely to be non-complaint with regular dialysis, fluid replacement etc $[23,24]$. In our study, substance abuse, alcoholism [25] and suicidal thoughts, attempts and deliberate self-harm are absent. The difference may be due to the collectivistic nature of the study population that promote increased family support, religious and social constraints [22] as well as emotional resilience. The lurking crisis of Bangladeshi dialysis patients, represented in this study is recent unemployment due to CKD which comes as a curse along with the profound physical disability. In a recent meta-analysis, patients on dialysis were reported to have higher rates of depression and increased risk of hospitalization due to psychiatric disorders than individuals undergoing conservative treatment and post-transplant patients. Those with Major Depressive Episode (MDE) [26] had a higher risk of death, hospitalization, or maintenance dialysis initiation within 12 months of MDE diagnosis compared with those without an MDE. Patients with both CKD and MDE have almost twice the risk of being hospitalized [25]. Several co-morbidity conditions like cerebrovascular disease hypertension, diabetes are found in the present study and others $[25,27,28]$. In patients on chronic hemodialysis therapy, depression is related closely to nutritional status and could be an independent risk factor for malnutrition [29].

\section{The relationship between CKD and depression in neuroimaging}

Kim, et al. demonstrated that in 27 patients with CKD, regional cerebral blood flow (rob) patterns correlate with symptom clusters of depressive mood. More recently, Nam, et al. studied 14 patients with CKD before and 6 months after HD and found correlations between reduced levels of depression, higher perfusion in the left middle temporal gyrus, and higher rob in the right Para hippocampal gyrus. These latter findings implicate the importance of the kidney-brain connection, not only in the neurologic aspect of cognition and learning but also in the affective presentation of many individuals with CKD, particularly with respect to the appearance of affective disorders [30]. Hemodialysis patients had more severe white matter disease and cerebral atrophy (sulci prominence $=2.3$ v 0.6; ventricular enlargement $=2.3$ v 0.9; hippocampal size $=1.3 \vee 1.0$ ) with all $p$-values $<0.001$. Hemodialysis patients also had a higher prevalence of small $(17.8 \%)$ and large $(7.8 \%)$ vessel infarcts than controls (combined $22 \%$ vs. $0 \%, p<0.001$ ) [31]. Patients with vascular diseases often have depression. In a sample of 15186 patients treated in a primary care setting, 
we observed that those with significant depressive symptomatology had a higher frequency of vascular disease than nondepressed patients. Approximately $8 \%$ of depressed patients had hypertension, $9 \%$ had ischemic heart disease, $13 \%$ had peripheral vascular disease, $7 \%$ had stroke, and $9 \%$ had heart failure. The corresponding percentages for non-depressed patients were $4 \%, 4 \%, 4 \%, 5 \%$, and $4 \%$, respectively. Silent stroke, stroke without neurological signs, is frequent in elderly depressed populations. In a Japanese sample, silent cerebral infarction was found in $83 \%$ of major depressives older than 65 years. Silent cerebral infarction was observed in $94 \%$ of patients with onset of first depressive episode after 65 years of age. Elderly depressives, and especially late-onset depressives, have white matter hyperintensities (WMHs) more frequently than no depressed individuals. WMHs correspond to areas of arteriolar ectasia, enlargement of perivascular spaces, and myelin pallor associated with arteriosclerotic changes of perforating arteries. Lesions in the basal ganglia are associated with depression. Approximately $40 \%$ to $75 \%$ of depressed elderly patients have lesions of the thalamus and basal ganglia, while only $5 \%$ of normal elderly controls have such lesions, and their lesions are smaller than the lesions of elderly depressives [32].

End-stage renal disease patients who have been on long-term hemodialysis tend to develop central nervous system complications [33]. The most common neurologic complications in the dialysis patient group include white matter changes, cerebral atrophy, osmotic demyelination syndrome, dialysis encephalopathy, hypertensive encephalopathy, intracranial hemorrhage, infarct, sinus thrombosis, and infection [34]. Lesion generation has been attributed to endothelial damage, giving rise to a pathological hemodynamic and cerebrovascular regulation which, in turn, is unable to maintain stable cerebral blood flow. This hypo-perfusion model has been shown to lead initially to an impaired protein synthesis, crucial in both cognitive and affective processing. Further vascular dysfunction culminates in the ischemic injury of specific tissue, subcortical white matter being especially sensitive due to its limited supply by terminal arterioles with little to no collateral flow [35]. The majority of studies in patients with ESRD have reported an association between depression and poor psychosocial and medical outcomes, with only a minority reporting no association. In a recent systematic review, Farrokhi, et al. identified 31 studies of 67,075 patients examining the association between depression and mortality in patients with ESRD receiving long-term dialysis. In 18 studies, the authors found that the mortality risk in patients on dialysis was 1.5 times higher in the presence of depressive symptoms independent of other confounding factors. They also found that this relationship was dose dependent, that is, the more severe the depression, the higher the risk of mortality [36]. Another potential biological mechanism that may lead to depression in patients with CKD and ESRD is the direct effect of comorbid cerebrovascular disease, which is highly prevalent in patients with kidney disease, on the mood regulatory functions of the brain. For example, specific post stroke lesions in the left anterior and left basal ganglia, and those close to the frontal pole, have been associated with depression. Cerebrovascular disease may also indirectly affect mood by increasing inflammation.

Further research is needed to identify biobehavioral mechanisms by which depression adversely affects renal disease outcomes [37].

\section{Limitation and Future Research}

Psychiatry is a stigmatized subject among common people in Bangladesh. Moreover, CKD patients were already irritable and noncompliant which made the data collection challenging. More finance would have increased the study sample. However, this pioneer study will set reference for further research. Neuroimaging using MRI would have added more information to our research. Further research is needed to identify bio-behavioral mechanisms by which depression adversely affects renal disease outcomes improvement of the dialysis treatment outcome would require.

\section{Conclusion}

Prevalence of MDD among CKD and ESRD patients propels the vicious cycle where dialysis treatment is undermined and the patients' overall health outcomes are compromised. Treatment of the physical ailments become more challenging when it is compounded with mental disorders such as MDD. Lack of education, shortage of overall government health funding, stigma of mental health conditions and scarcity of desired resources, especially in developing countries such as Bangladesh, means that issue of MDD goes seemingly unaddressed, which further enhances the complexity of the issue. Thus, depressive disorder deserves more attention in context to the management of dialysis patients. Improvement of dialysis treatment outcome relies on utilization of a multifaceted intervention approach that encompasses social, political, biological and cultural models of health to address the proper diagnosis and treatment of depressive disorder.

\section{Funding}

The study was done on self-funding.

\section{References}

1. Finkelstein FO, Finkelstein SH (2000) Depression in chronic dialysis patients: Assessment and treatment. Nephrol Dial Transplantat 15: 1911-1913.

2. Teles F, Azevedo VF, Miranda CT, Miranda MP, Teixeira Mdo C, et al. (2014) Depression in hemodialysis patients: The role of dialysis shift. Clinics 69: 198-202. 
3. Kimmel PL (2002) Depression in patients with chronic renal disease: What we know and what we need to know. $J$ Psychosom Res 53: 951-956.

4. De-Nour AK, Shaltiel J, Czaczkes JW (1968) Emotional reactions of patients on chronic hemodialysis. Psychosom Med 30: 521-533

5. De-Nour AK (1982) Social adjustment of chronic dialysis patients. Am J Psychiatry 139: 97-100.

6. Kimmel PL, Weihs K, Peterson RA (1993) Survival in hemodialysis patients: The role of depression. J Am Soc Nephrol 4: 12-27.

7. Shirazian S, Grant CD, Aina O, Mattana J, Khorassani F, et al. (2017) Depression in chronic kidney disease and end-stage renal disease: Similarities and differences in diagnosis, epidemiology, and management. Kidney Int Rep 2: 94-107.

8. Cukor D, Cohen SD, Peterson RA, Kimmel PL (2007) Psychosocial aspects of chronic disease: ESRD as a paradigmatic illness. J Am Soc Nephrol 18: 3042-3055.

9. Levenson JL, Glocheski S (1991) Psychological factors affecting end-stage renal disease: A review. Psychosomatics 32: 382-389.

10. Watnick S, Wang PL, Demadura T, Ganzini L (2005) Validation of 2 depression screening tools in dialysis patients. Am J kidney Dis 46: 919-924.

11. Killingworth A, Van Den Akker O (1996) The quality of life of renal dialysis patients: Trying to find the missing measurement. Int J Nurs Stud 33: 107-120.

12. Stein MB, Cox BJ, Afifi TO, Belik SL, Sareen J (2006) Does co-morbid depressive illness magnify the impact of chronic physical illness? A population-based perspective. Psychological Medicine 36: 587-596.

13. Lopes AA, Albert JM, Young EW, Satayathum S, Pisoni $\mathrm{RL}$, et al. (2004) Screening for depression in hemodialysis patients: Associations with diagnosis, treatment, and outcomes in the DOPPS. Kidney Int 66: 2047-2053.

14. Cilan H, Oguzhan N, Unal A, Turan T, Koc AN, et al. (2012) Relationship between depression and proinflammatory cytokine levels in hemodialysis patients. Ren Fail 34: 275278.

15. Steele TE, Baltimore D, Finkelstein SH, Juergensen $\mathrm{P}, \mathrm{Kli}-$ ger AS, et al. (1996) Quality of life in peritoneal dialysis patients. J Nerv Ment Dis 184: 368-374.

16. Beck AT, Steer RA, Brown GK (1996) Beck depression inventory-II.

17. Wuerth DB, Finkelstein SH, Schwetz O, Carey H, Kliger AS, et al. (2002) Patients' descriptions of specific factors leading to modality selection of chronic peritoneal dialysis or hemodialysis. Perit Dial Int 22: 184-190.

18. Lambert MJ, Hatch DR, Kingston MD, Edwards BC (1986) Zung, beck, and hamilton rating scales as measures of treatment outcome: A meta-analytic comparison. J Consult Clin Psychol 54: 54-59.

19. Snaith RP, Taylor CM (1985) Rating scales for depression and anxiety: A current perspective. Br J Clin Pharmacol 19: 17S-20S

20. Kimmel PL (2001) Psychosocial factors in dialysis patients. Kidney Int 59: 1599-1613.

21. Kimmel PL, Thamer M, Richard CM, Ray NF (1998) Psychiatric illness in patients with end-stage renal disease. Am J Med 105: 214-221.
22. Kop WJ, Seliger SL, Fink JC, Katz R, Odden MC, et al. (2011) Longitudinal association of depressive symptoms with rapid kidney function decline and adverse clinical renal disease outcomes. Clin J Am Soc Nephrol 6: 834-844.

23. Armaly Z, Farah J, Jabbour A, Bisharat B, Abd-El Qader A, et al. (2012) Major depressive disorders in chronic hemodialysis patients in Nazareth: Identification and assessment. Neuropsychiatr Dis Treat 8: 329-338.

24. Kimmel PL, Peterson RA (2006) Depression in patients with end-stage renal disease treated with dialysis: Has the time to treat arrived? Clin J Am Soc Nephrol 1: 349-352.

25. Wang LJ, Chen CK (2012) The psychological impact of hemodialysis on patients with chronic renal failure. Renal failure-The facts $217-236$.

26. Felger JC, Lotrich FE (2013) Inflammatory cytokines in depression: Neurobiological mechanisms and therapeutic implications. Neuroscience 246: 199-229.

27. McDermott LM, Ebmeier KP (2009) A meta-analysis of depression severity and cognitive function. J Affect Disord 119: 1-8.

28. Balaban ÖD, Aydin E, Keyvan A, Yazar MS, Tuna Ö, et al. (2017) Psychiatric comorbidity, sexual dysfunction, and quality of life in patients undergoing hemodialysis: A case-control study. Noro Psikiyatr Ars 54: 137-142.

29. Makara Studzińska M, Koślak A (2011) Depression symptoms among patients with end stage renal disease and among primary health care patients. Arch Psychiat Psychother 3: 5-10.

30. Moodalbail DG, Reiser KA, Detre JA, Schultz RT, Herrington JD, et al. (2013) Systematic review of structural and functional neuroimaging findings in children and adults with CKD. Clin J Am Soc Nephrol 8: 1429-1448.

31. Drew DA, Bhadelia R, Tighiouart $H$, Novak V, Scott TM, et al. (2013) Anatomic brain disease in hemodialysis patients: A cross-sectional study. Am J Kidney Dis 61: 271-278.

32. Alexopoulos GS, Bruce ML, Silbersweig D, Kalayam B, Stern E (1999) Vascular depression: A new view of late-onset depression. Dialogues Clin Neurosci 1: 68-80.

33. Mahoney CA, Arieff Al (1982) Uremic encephalopathies: Clinical, biochemical, and experimental features. Am J Kidney Dis 2: 324-336.

34. Ağıldere AM, Kurt A, Yildırım T, Benli S, Altınörs N (2001) MRI of neurologic complications in endstage renal failure patients on hemodialysis: Pictorial review. Eur Radiol 11: 1063-1069.

35. Turk BR, Gschwandtner ME, Mauerhofer M, Löffler-Stastka H (2015) Can we clinically recognize a vascular depression? The role of personality in an expanded threshold model. Medicine 94: e743.

36. Fan L, Sarnak MJ, Tighiouart H, Drew DA, Kantor AL, et al. (2014) Depression and all-cause mortality in hemodialysis patients. Am J Nephrol 40: 12-18.

37. O'Brien ME (1990) Compliance behavior and long-term maintenance dialysis. Am J Kidney Dis 15: 209-214. 